\title{
Amicus curiae. Análisis antropológico y de género en el caso de violación sexual contra niña mam y su resolución con base en el derecho comunitario indígena
}

\author{
AURA ESTELA CUMES SIMÓN
}

Introducción

Amicus Curiae. Anthropological and Gender Analysis of a Case of Sexual Violence against a Mam

Child and its Resolution by the Indigenous Communitarian Law

Aura Estela Cumes Simón

Comunidad de Estudios Mayas,

Guatemala

aecumess@yahoo.com

Desacatos 57 ,

mayo-agosto 2018, pp. 180-195 n marzo de 2015, me fue solicitado un amicus curiae para presentarlo a la Corte de Constitucionalidad de Guatemala (CC). El objetivo era aportar un criterio experto sobre la resolución de un caso de violación, con base en el derecho comunitario indígena de Comitancillo, San Marcos, que fue declarado ilegal por instancias del derecho estatal. Se trataba del caso de violación sexual contra la niña Vilma Carolina Cardona Coronado, de diez años de edad, por parte del adolescente Esvin Abel García Cardona, de 14 años de edad, ambos indígenas.

El caso me pareció complejo. Se trataba de hablar de un problema grave, como la violación sexual a una niña, y también de reflexionar sobre la resolución de las autoridades indígenas, en medio de un contexto de racismo colonial. El camino más fácil, que suele seguir cualquiera de las disciplinas en las que nos formamos, incluyendo la jurisprudencia, es pensar y tomar decisiones desde un solo lugar. Como se nota en los discursos que se esgrimieron, las fiscales hacen una defensa de la niña en tanto mujer, persona individual y víctima, como si se tratara de alguien huérfano de su familia, de su comunidad y de su ser indígena. Con ello, niegan la existencia de las autoridades y del derecho indígena. En oposición, esto provoca una defensa de la autoridad y del derecho indígena, con el riesgo de olvidar a la víctima.

La complejidad del problema que viven las mujeres indígenas pone en evidencia las limitaciones de los marcos bipolares para analizar y decidir sobre la realidad, a la que terminan encuadrando por la fuerza del pragmatismo. Me encontré ante el dilema de si sería útil un amicus $\mathbf{c u}$ riae con demasiados matices, cuando se esperan criterios concluyentes. 
Busqué enlazar los recursos de la antropología jurídica con los estudios de género y feminismo, en su tendencia anticolonial y descolonial, con reflexiones propias, que no responden exactamente a estos marcos explicativos. Tanto la transdisciplinariedad como la interdisciplinariedad evitan que los matices de una realidad compleja queden ocultos en resoluciones pragmáticas, unidimensionales y simplificadas en exceso. Con estos referentes analíticos, procuré arribar a las reflexiones que expongo en este documento.

El análisis y la subsecuente argumentación que presento en el amicus curiae y en este artículo se desprenden de la revisión cuidadosa de la documentación generada en el caso, tanto por las autoridades indígenas como por los agentes del derecho estatal. Es decir, me centré en la interpretación de los discursos registrados. En la documentación, se hace evidente que la crítica y la oposición a la resolución no acontecen en un clima de horizontalidad y equivalencia entre el derecho comunitario indígena y el derecho estatal, sino de predominio del segundo sobre el primero.

Luego de un largo proceso, el 10 de marzo de 2016, la CC emitió una sentencia favorable a las autoridades indígenas y su resolución. En el documento de sentencia no se cita este amicus curiae; sin embargo, su razonamiento final coincide con uno de los criterios aquí sostenidos, cuando la CC observa que la utilización del argumento de que en Guatemala sólo existe una forma de juzgar, por medio de una lectura dogmática de la Constitución Política de la República, para negar con base en ello la existencia de las autoridades indígenas, sólo ocurre en un contexto de vigencia de la dominación colonial.

\section{De los hechos y su juzgamiento en el derecho comunitario indígena}

En el acta 13-2012, del domingo 10 de junio de 2012, el Consejo Municipal de Alcaldes Comunitarios del Municipio de Comitancillo, San Marcos, deja constancia de uno de los problemas tratados en esa ocasión: la violación de una niña. El acta refiere que se encuentran reunidos, por el lado de las autoridades, el señor Emiliano Tomás Godínez, alcalde principal mam y los otros integrantes del Consejo Municipal de Alcaldes Comunitarios; el señor Faustino Crisóstomo García, alcalde principal del Consejo de Principales y los otros integrantes. Por la parte que ha ofendido están presentes el señor Antonio García Tomás, la señora Ángela Cardona Rosario y el joven Esvin Abel García Cardona. Por la parte ofendida, el señor Álvaro Eladio Cardona García, la señora Rosa Coronado Marroquín y la niña Vilma Carolina Cardona Coronado.

Como parte del proceso de conocimiento del problema, el señor Antonio García Tomás expone: "soy el padre del menor Esvin Abel García Cardona, y que en fecha del Viernes Santo, de esta Semana Santa [...] abusó sexualmente de la niña [Vilma] Carolina Cardona Coronado". El acta no hace constar la edad de los menores. Se conoce que en el momento de los hechos el adolescente tenía 14 años y la niña diez. De acuerdo con los relatos del padre del joven, cuándo él se enteró de lo ocurrido, llevó a la niña agredida al hospital nacional, pero los médicos, al enterarse del hecho, lo remitieron al ministerio público para comenzar un proceso penal. Se desconoce, o no se hace constar, dónde se encontraban los padres de la niña y si la acompañaron al hospital.

Al escuchar los hechos, las autoridades comunitarias piden a ambos menores que con toda libertad hablen de lo sucedido. Se le pregunta al joven Esvin Abel García Cardona si es cierta la acusación que pesa sobre él, y dice: "realmente fue cierto y no me acuerdo por qué lo hice”. Se le pregunta a la niña Vilma Carolina Cardona Coronado: "¿es cierto que el joven abusó de ti??". La niña responde: "sí, fue así”. Luego de escuchar la declaración de los menores, el Consejo analiza y acuerda con los padres de familia las siguientes responsabilidades: 
a) Llevar a la niña a una comadrona [...]; b) llevar [a la niña] ante una ginecóloga [...]; c) llevar la niña ante un psicólogo [...]. Conociendo los resultados de las evaluaciones, el Consejo analizará y procederá a deliberar cual será el castigo o medida de corrección que se le aplicará al menor, al considerar que es una falta grave a las normas y buenas costumbres. También [una] falta de respeto hacia sus padres y a la madre tierra. Por consiguiente, habrá que llevar un proceso para que se cumpla lo que el Consejo decida en una futura reunión de diálogo.

El domingo 17 de junio de 2012, el Consejo Municipal de Alcaldes Comunitarios y el Consejo Municipal de Principales se reúnen por segunda vez para dar seguimiento al problema, según consta en el acta 14-2012. Están presentes, además de las autoridades, los padres del menor acusado y la niña víctima. Ambas familias son originarias de la aldea Porvenir Candelaria, municipio de Comitancillo. Según se describe en el acta, el Consejo Municipal de Autoridades Comunitarias toma un tiempo para deliberar ampliamente sobre el problema:

Teniendo como base las leyes vigentes de nuestro país, así como los convenios y tratados internacionales relacionados a Pueblos Indígenas, léase art. 66 de la Constitución Política de la República de Guatemala, art. 8, 5, 18 del Convenio 169 sobre Pueblos Indígenas y Tribales en países independientes. Igualmente, el Consejo conoce los resultados de los exámenes solicitados a la comadrona [...], a la ginecóloga [...], los cuales indican que el estado de salud de la menor Vilma Carolina Cardona Coronado es bastante bueno y no presenta síntomas de embarazo.

Se menciona también el diagnóstico del psicólogo. Sin embargo, no se especifica en el acta el estado emocional de la menor.
El Consejo Municipal de Alcaldes Comunitarios, conociendo los resultados anteriores y en base a las normas y costumbres del Pueblo Mam: ResuelVEN: a) Aceptar los documentos en mención. b) Al escuchar la conformidad de los padres de los menores en relación al caso. c) Aceptar como ciertos los acuerdos a que han llegado los padres de los menores, como también de las responsabilidades adquiridas. De igual forma el Consejo Municipal de Alcaldes Comunitarios atendiendo la gravedad del caso analiza las medidas de corrección siguientes: MORAL: Consiste en que el menor Esvin Abel García Cardona debe pedir perdón de rodillas a sus padres, a los padres de la menor y en especial a la niña Vilma Carolina Cardona y el compromiso de no volver a hacer una vez más. FísicA: el menor deberá recibir de parte de sus padres [...] de doce a veinticinco azotes, conocido como almuda o arroba. ECONÓMICA: El padre de familia del menor infractor deberá pagar los gastos en los cuales incurra este problema hasta que el estado de salud de la menor se considere adecuado o bueno. Asumir por un espacio de seis meses o un año a partir de la resolución final del caso, el estricto control del estado de salud de la niña $[. .$.$] y que asumirá los gastos eco-$ nómicos necesarios [...]. Solicitar al Juzgado de Primera Instancia de Trabajo y Previsión Social de la Niñez y Adolescentes en conflicto con la ley penal a efecto se tome en cuenta y se considere lo que intervenimos.

El miércoles 27 de julio del mismo año, en el mismo lugar de reunión, se concentran las mismas personas que han intervenido en los dos momentos pasados. Están presentes las autoridades, el joven que ha reconocido su responsabilidad en la violación y sus padres, y la menor agredida con sus padres. Todo esto se hace constar en el acta 15-2012. El alcalde principal mam consideró la violación como "una falta grave dentro de las normas y las buenas costumbres del pueblo mam”. Luego de un largo 


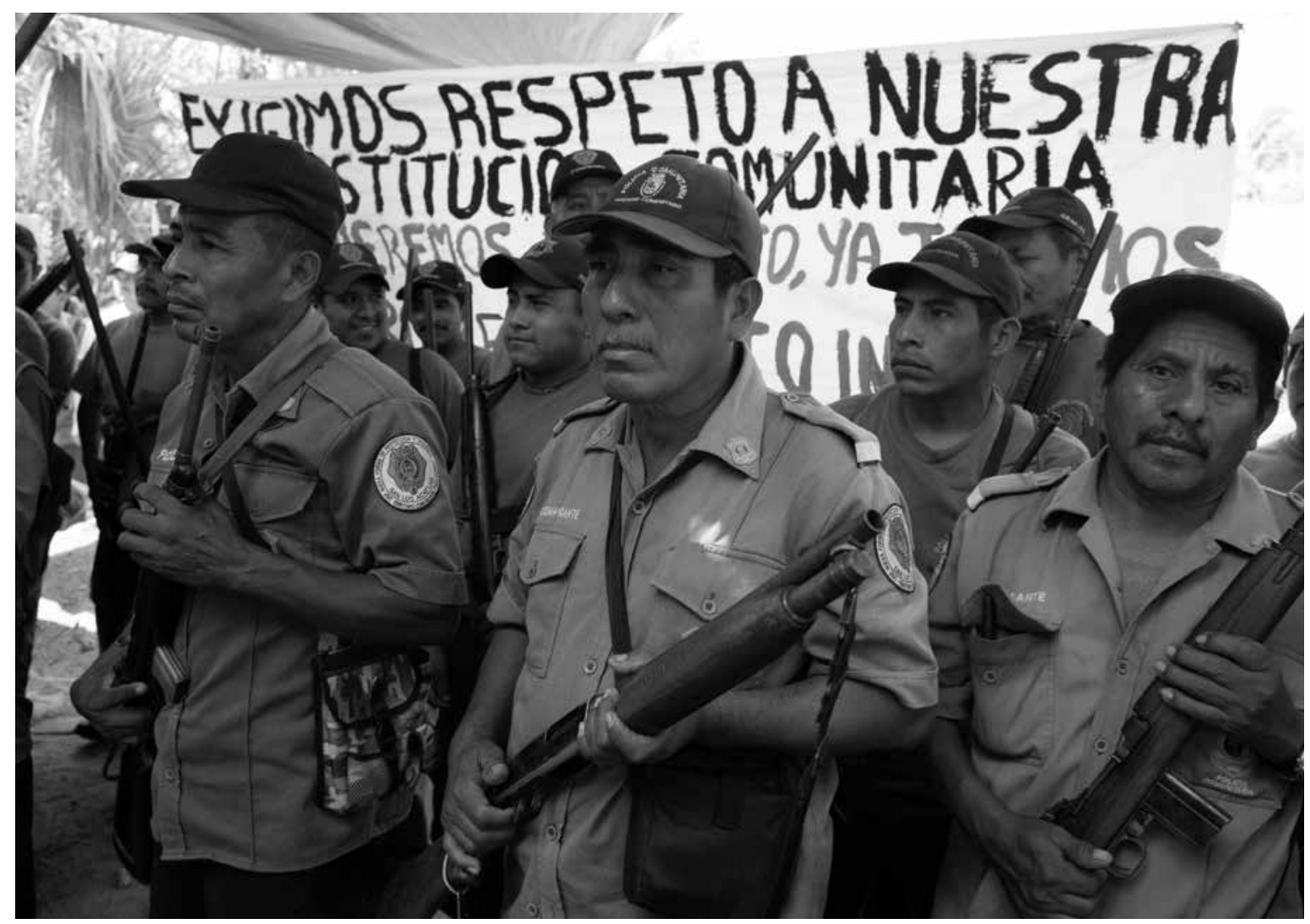

Prometeo Lucero - Lectura del decreto estatal que regularía a la Policía Comunitaria, San Luis Acatlán, Guerrero, 17 de febrero de 2013.

diálogo, las familias que intervienen en este caso “están totalmente de acuerdo en perdonarse mutuamente; como también asumen las responsabilidades adquiridas". En este tercer momento se aplican las medidas de corrección acordadas:

MORAL: El menor Esvin Abel García Cardona pide perdón de rodillas ante los padres de la niña Vilma Carolina Cardona Coronado y los padres de él diciendo de la siguiente manera: "Yo Esvin Abel García Cardona pido perdón por lo que ya hice, estoy seguro que ya les quité la vergüenza y ya les puse en un lugar muy bajo en la sociedad, estoy totalmente arrepentido, les prometo que de aquí en adelante me comportaré mejor y trataré de mejorar y respetar siempre a mis mayores, a mis vecinos y demás personas". FísICA: El menor recibió unos azotes de parte de sus padres para cumplir con lo establecido, es decir para corregirlo, todo esto se realizó de forma pública. ECONÓMICA: El señor Antonio García Tomás está anuente y seguirá sufragando los gastos necesarios para su total recuperación de la niña Vilma Carolina Cardona Coronado. Lo resuelto se fundamenta en el artículo 66 de la Constitución Política de la República de Guatemala y artículos 5 y 8 del Convenio 169 sobre Pueblos Indígenas y Tribales.

Luego de esta sanción:

El Honorable Consejo Municipal de Alcaldes Comunitarios de Comitancillo, San Marcos, SOlicita 
al Juzgado de Primera Instancia de Trabajo y Previsión Social de la Niñez y Adolescentes en Conflicto con la Ley Penal [...] tomar en cuenta lo resuelto y actuado por este honorable consejo, como autoridad Ancestral del pueblo Maya-Mam.

\section{El derecho estatal frente a la resolución del derecho comunitario indígena}

De acuerdo con los expedientes analizados, la respuesta de las instancias del derecho estatal frente a este caso, en principio, no fue unívoca. El juez de Primera Instancia de Trabajo y Previsión Social, Niñez y Adolescencia, y de Adolecentes en Conflicto con la Ley Penal de San Marcos resolvió sobreseimiento del caso y reconoció la legitimidad de la resolución de las autoridades indígenas. Argumentó que nadie puede ser juzgado dos veces por el mismo delito. Esta resolución es favorable a la demanda hecha por las mismas autoridades indígenas y a la del abogado defensor del menor acusado, propuesto por el Instituto para la Defensa Pública Penal. Inconforme, la Fiscalía de Menores o de la Niñez del Ministerio Público de San Marcos ${ }^{1}$ interpuso un recurso de apelación contra la resolución del juez de Primera Instancia y alegó ilegalidad "de las costumbres indígenas", violación a los derechos humanos del joven infractor e insatisfacción con la resolución en virtud de la gravedad del caso. Como respuesta, la Sala de la Corte de Apelaciones de la Niñez y la Adolescencia dio lugar al recurso de apelación y avaló lo dicho por la fiscalía. Además, la Corte señala que la Ley contra el Femicidio y Otras Formas de Violencia Contra la Mujer establece la prohibición de invocar costumbres o tradiciones para exculpar a cualquier agresor. Con esta posición, autoriza perseguir legalmente a las autoridades indígenas al resolver: "certifíquese lo conducente al ministerio público para que inicie la investigación de lo denunciado con el objeto de que se deduzcan a los miembros de la comunidad, las responsabilidades a que haya lugar". ${ }^{2}$ De esta manera, una resolución en el marco del derecho comunitario indígena, satisfactoria para las partes en conflicto, se convirtió en delito bajo instancias del derecho estatal.

En correspondencia con estas posturas, también se denegaron los recursos de amparo solicitados por el abogado defensor a favor del menor juzgado en el derecho comunitario indígena. La defensa del menor solicitó dejar incólume la resolución emitida por el juez de Primera Instancia, con los siguientes argumentos: ${ }^{3}$ a) que lo juzgado por las autoridades indígenas tiene legitimidad pues su actuación está garantizada por las leyes nacionales e internacionales; b) la resolución del juez es respetuosa del ejercicio "de las costumbres indígenas"; c) la parte agraviada ha quedado satisfecha con la sanción impuesta como lo manifestó en audiencia intermedia; d) la decisión de la Corte de la Niñez y la Adolescencia no se apega a derecho y violenta los derechos de "los grupos étnicos" e irrespeta "sus costumbres y tradiciones", lo que contraviene los artículos 46 y 66 de la Constitución Política de la República de Guatemala y el artículo 9 del Convenio 169.

El Gran Consejo Nacional de Autoridades Ancestrales Maya, Garífuna y Xinca de Ixim Ulew ha actuado como tercero interesado, por mediación del señor Diego Cotiy Más. Su fundamentación se basa en los siguientes puntos: ${ }^{4}$ a) bajo el prisma del pluralismo jurídico, el Estado guatemalteco, por medio de la Corte Suprema de Justicia,

1 Agente fiscal Miriam Iliana Barrios de Alvarado.

2 Archivo General de Tribunales, acta 00044-2012-00131, of. 1ำ Sala de la Corte de Apelaciones de la Niñez y la Adolescencia, p. 2.

3 Archivo General de Tribunales, amparo nuevo, interpuesto por Humberto Rafael Hidalgo Caballeros, firmado por el doctor Reyes Ovidio Girón Vásquez, 20 de noviembre de 2012.

$4 \quad$ Archivo General de Tribunales, amparo 1552-2012, of. 4ำ p. 2. Diego Cotiy Más, por quien firma Juan Jeremías Castro Simón. Exp. 14678-2014, of. 6․․ 
ha reconocido la jurisdicción y la competencia de las autoridades indígenas para administrar justicia; b) la autoridad indígena de Comitancillo conoció y juzgó conforme a sus principios y valores cosmogónicos un hecho para el cual fue requerida, facultad que está regulada en los artículos 203, 66 de la Constitución Política de la República, y artículos 44 y 46 constitucionales, que incorporan los artículos 8 y 9 del Convenio 169 de la Organización Internacional del Trabajo; c) la autoridad indígena de Comitancillo no se atribuyó facultades que no le competen, porque éstas están legalmente reconocidas; d) la legitimación de la autoridad indígena para juzgar este hecho fue conferida por la comunidad indígena, por los interesados, la familia del victimario, la familia de la víctima y todos los que aportaron y tuvieron interés en el asunto; e) las autoridades indígenas sí tienen facultad para conocer casos de violación; f) no se contravino la Ley Contra el Feminicidio y Otras Formas de Violencia Contra la Mujer porque no se exculpó al agresor, sino que se le sancionó; g) no se vulneraron los derechos humanos del agresor, pues la sanción se fundamenta en los principios de la cosmovisión maya; h) lo dictado por los tribunales estatales criminaliza el ejercicio del derecho indígena y a sus autoridades ancestrales, provoca destrucción del derecho indígena y promueve etnocidio; i) lo actuado por los tribunales representa un retroceso para los avances del pluralismo jurídico reconocido por la Corte Suprema de Justicia; j) se perpetúa un Estado racista con las resoluciones contra las autoridades indígenas emitidas por los tribunales en este caso.

\section{Derecho indígena y derecho estatal: más allá de la ley}

Como se observará en adelante, para los funcionarios que intervinieron en la resolución de este caso, el problema no radicaba sólo en la manera en que se juzgó el delito de violación, sino en la "ilegalidad" de "las costumbres indígenas" y de quienes se asumen como autoridades en el ejercicio de la justicia. Esta posición les llevó a comparar el derecho indígena con organizaciones delictivas que deberían ser desestructuradas. Por su lado, la defensa del adolescente acusado y el representante de las autoridades indígenas buscaron demostrar a los tribunales no sólo el reconocimiento legal del derecho indígena por parte del Estado guatemalteco, sino la legitimidad histórica de su existencia, otorgada por las comunidades indígenas. Sin embargo, la ley se colocó como absoluta y determinante. En la argumentación de los funcionarios, el derecho estatal no sólo es superior, sino que ostenta una existencia exclusiva al sostener que no hay más derecho que el oficial. Aún más, el discurso penal generado en este caso fue diseñado para señalar al derecho indígena y sus autoridades como enemigos del Estado, lo que justificaba una evidente criminalización.

La dureza de este lenguaje jurídico es contradictoria con la diversidad de pueblos y normativas que coexisten en el suelo guatemalteco, realidad que conforma un espacio rico para el ejercicio del pluralismo jurídico, en el que ambos sistemas, sin jerarquías, podrían funcionar, dialogar o cuestionarse mutuamente en una práctica político-jurídica novedosa. Para las antropólogas colombianas Esther Sánchez Botero y Herinaldy Gómez Valencia (2008), el pluralismo jurídico se presenta cuando en un mismo espacio geográfico coexisten pueblos con historias, culturas y sistemas normativos distintos. En el caso de las sociedades latinoamericanas, mediante el pluralismo jurídico, el Estado reconoce, respeta e interactúa con el sistema normativo de los pueblos indígenas.

El hecho de no encontrar en este lenguaje jurídico atisbos de reconocimiento, intención de comprensión o diálogo, y menos aún, alguna propuesta de coordinación interlegal, obligó a recurrir a preguntas como: ¿por qué el derecho estatal asume un papel intervencionista, destructor y castigador de los pueblos indígenas cuando hay un reconocimiento 
legal, nacional e internacional, de los pueblos y su derecho propio? ¿Qué le da al derecho estatal, representado por los funcionarios que intervinieron en el caso, autoridad para criminalizar al derecho indígena y sus autoridades? La respuesta no se encuentra sólo en el campo jurídico, debe buscarse en la historia que le ha dado forma a las sociedades en que vivimos y al derecho estatal mismo. En esta historia tiene sentido un lenguaje supremacista, exclusivista y castigador de la ley, como se analizará en el siguiente apartado.

\section{Negación y criminalización del derecho indígena: un problema de colonialismo interno}

La agente fiscal de la Fiscalía de Menores o de la Niñez del Ministerio Público de San Marcos argumentó lo siguiente, contra la resolución del juez de Primera Instancia y como fundamento del recurso de apelación:

Lo resuelto por el juez de primer grado no es legal ya que ordenó el sobreseimiento del proceso argumentando que el adolescente ya había sido sancionado conforme a las costumbres indígenas, olvidando que en Guatemala únicamente existe un sistema jurídico reconocido legalmente, no existe otro ordenamiento aplicable como el indígena a que hace referencia el juez. ${ }^{5}$

Esta posición fue avalada por la Sala de la Corte de Apelaciones de la Niñez y de la Adolescencia, que establece:

Lo resuelto no es procedente en virtud de que los comuneros del lugar [...] no constituyen un órgano jurisdiccional legalmente creado por la ley para impartir justicia [...]. Por ello las autoridades reconocidas por la población indígena no pueden actuar como jueces, sino como órganos de comunicación y negociación [...] corresponda al Organismo Judicial, ya que es en este poder del Estado en donde se juzga y resuelve [...] el artículo 203 de nuestra Carta Magna regula que la justicia se imparte de conformidad con la Constitución y leyes de la República. $^{6}$

Sería provechoso analizar con mayor detenimiento por qué esta tradición legalista no repara en la capacidad de destruir que tiene la ley cuando es aplicada fuera de una historia y un contexto de poder. Cuando la Sala de la Corte de Apelaciones de la Niñez y de la Adolescencia dice "nuestra Carta Magna regula que la justicia se imparte de conformidad con la Constitución y leyes de la República”, ignora que el derecho indígena precede al mismo Estado. Los pueblos indígenas y sus formas actuales de organización son sobrevivientes de la violencia colonial y estatal, por eso las leyes nacionales e internacionales deben reconocerlos como sujetos de derechos colectivos. La argumentación de la ley en el caso aboga en cambio por la destrucción de una de sus formas organizativas. Esto significaría que la dominación colonial y la estructura racista del país se materializan en la misma aplicación de la ley, como se ha hecho desde cinco siglos atrás.

Robert Carmack (citado en Esquit y Ochoa, 2006: 37) afirma que la dominación española restringió el derecho maya, lo cual marcaría la historia de este sistema jurídico hasta la actualidad. Concuerda con Jorge Solares (2000) en que para comprender la existencia del derecho maya hay que entender que la colonización no sólo produjo una oposición y jerarquización entre las normas oficiales y las mayas, sino que les otorgó estatus desiguales. En este proceso, el derecho indígena y el estatal entraron en

5 Archivo General de Tribunales, acta 00044-2012-00131, of. 1, 1 de octubre de 2012, Sala de la Corte de Apelaciones de la Niñez y la Adolescencia, p. 2.

6

Ibidem, p. 4 
contradicciones muchas veces, pero también desarrollaron ciertas formas de coincidencias (citado en Esquit y Ochoa, 2006). No sería necesario recordar la importancia de observar la historia que ha dado forma a este país y sus instituciones, si no fuera porque está siendo ignorada, en este caso. Pasar por alto la historia lleva a agredir la existencia misma de los pueblos indígenas, como se observa en el siguiente argumento de la Sala de la Corte de Apelaciones de la Niñez y la Adolescencia:

Ninguna otra autoridad puede intervenir en la impartición de justicia y en consecuencia, nadie puede ser juzgado por tribunales especiales ni por procedimientos que no están preestablecidos legalmente como es caso de que se juzga, porque al dar validez a lo actuado por las personas que intervinieron en este caso, se da vía libre a que en Guatemala impere la anarquía e impunidad, ya que cualquier persona podría acogerse a tribunales especiales no reconocidos por la ley. ${ }^{7}$

Asemejar el derecho indígena a tribunales especiales, a anarquía e impunidad, es, en principio, una comparación desafortunada que puede tener implicaciones políticas y legales profundas, pues no sólo se degrada sino que se amenaza su existencia. El conflicto armado interno en este país ha mostrado el carácter funesto de los tribunales especiales, reconocidos por sus fines represivos, criminales y desestructurantes del tejido social. Estos tribunales han actuado en contextos particulares de violencia e impunidad. El derecho indígena, por el contrario, no es coyuntural, pues ha tenido una permanencia en el tiempo. Además, cuenta con el reconocimiento social en las aldeas o municipios en los que actúa. Es contraproducente pensar que el derecho indígena es criminal, represor y desestructurante del tejido social cuando ha procurado la regulación de las relaciones sociales cuando el Estado ha estado ausente o presente en su versión represiva. Por ello, y apelando a la moderación, se interpretará que esta infeliz comparación del derecho indígena con tribunales especiales u organizaciones criminales no es un asunto de mala fe, sino de un hondo desconocimiento de la historia de Guatemala, los pueblos indígenas y el devenir del derecho indígena.

El antropólogo Jorge Solares, en referencia a la necesidad de que las múltiples disciplinas actúen en conjunto para comprender los problemas sociales de este país y sobre las limitaciones de una comprensión sólo legalista, plantea: “Guatemala no es un problema jurídico, es un problema social dentro del cual lo jurídico no es sino uno de sus elementos" (2000: 15). Los problemas suscitados en un país diverso y desigual son multicausales y multifactoriales. Como consecuencia, sus explicaciones y soluciones no pueden ser sino multisectoriales y transdisciplinarias:

Esto equivale a decir que no conviene examinar el asunto de lo jurídico encerrados en lo jurídico; lo pertinente es abordar la temática en correspondencia con otros fenómenos de la realidad social que no sólo es compleja sino que está interrelacionada en una estructura, es decir, la integración articulada de partes que sólo tienen sentido dentro del todo (2000: 16).

Es necesario reconocer que el profundo desconocimiento, negación y criminalización del derecho indígena, como el que se observa en este caso, responde a una estructura de dominación sobre los pueblos indígenas que puede nombrarse como colonialismo interno. El carácter colonial del Estado y la sociedad guatemalteca se pone en evidencia cuando la ley, la religión, la cultura, la política, la economía y el pensamiento occidental adquieren una existencia supremacista que ignora la historia,

$7 \quad$ Ibid., p. 5 


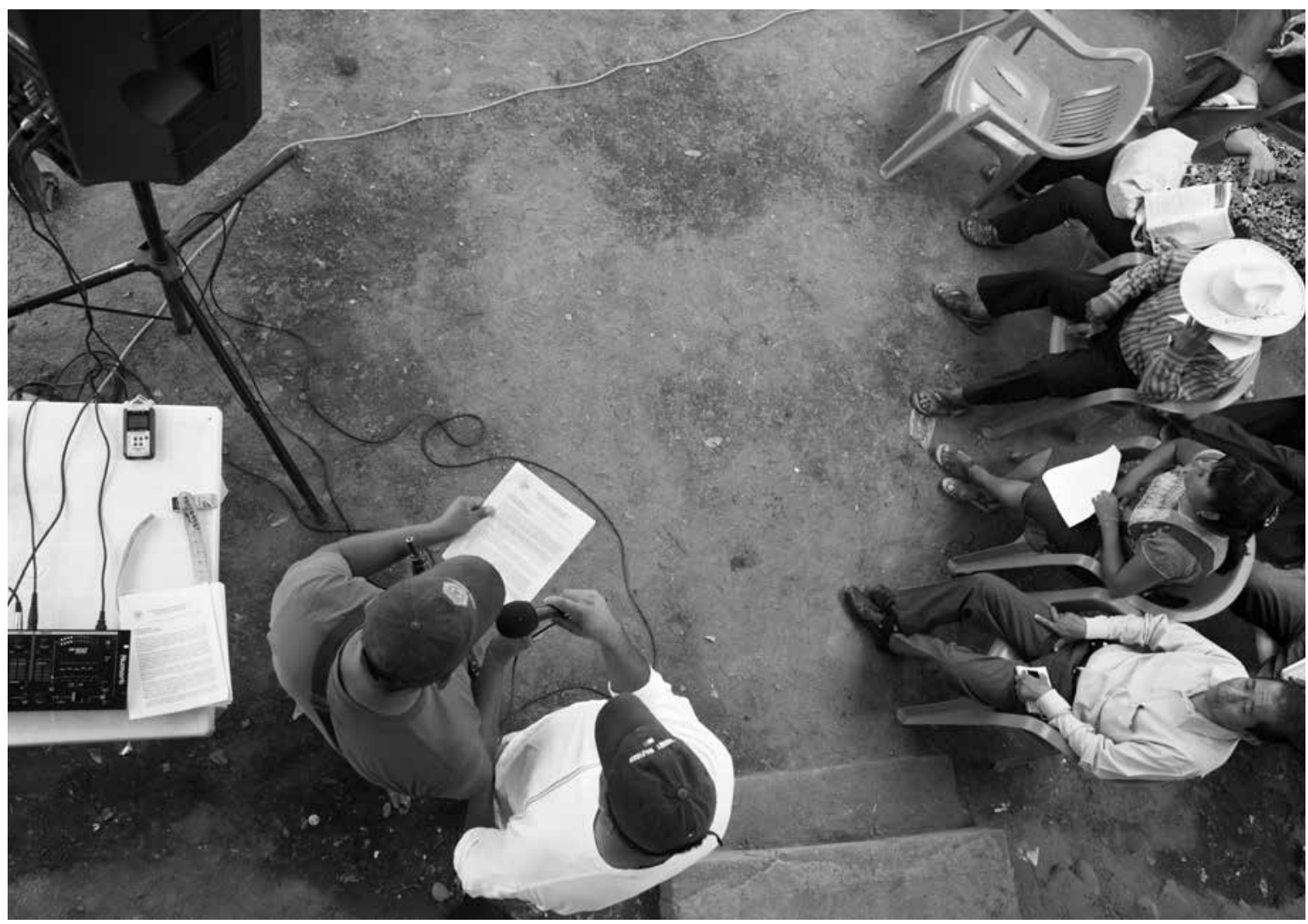

Prometeo Lucero • Encuentro Estatal de Justicia Comunitaria, San Luis Acatlán, Guerrero, 17 de febrero de 2013.

la autonomía y la autorregulación a la que tienen derecho los pueblos indígenas. Hay colonialismo interno cuando la jurisprudencia occidental ocupa un lugar exclusivo en sociedades étnicamente plurales. El colonialismo está vinculado al racismo cuando los pueblos racializados como inferiores son tenidos como bárbaros, incapaces de gobernarse a sí mismos y de generar sus propios modelos de vida. En un orden colonial, se supone que los pueblos indígenas deben ser controlados por quienes se arrogan una existencia supremacista, sin importar la profunda y peligrosa ignorancia que subyace en sus juicios. Pensar en los pueblos indígenas sólo como folclor representa una caricaturización de su existencia en tanto sujetos políticos e históricos; sin embargo, es así como una agente fiscal los ve:
Honorables magistrados, el ministerio público respetuosamente solicita se confirme en todos sus extremos la resolución impugnada con el único objeto de respetar el imperio de la ley y garantizar la seguridad jurídica que debe prevaler en todo Estado de derecho. Es muy distinto que en Guatemala se respeten las costumbres de los pueblos indígenas tales como sus trajes típicos, cofradías, procesiones, etc., a aceptar que en casos de impacto social, puedan sus autoridades locales juzgar y ejecutar lo juzgado, siendo estas facultades conferidas constitucionalmente, exclusivamente a los jueces de nuestro país. ${ }^{8}$

Archivo General de Tribunales, amparo 1552-2012, of. $4^{\circ}$, p. 1. Ana Karina Orozco Barrios, agente fiscal, Fiscalía de Menores de la Niñez, Ministerio Público. 


\section{La violación como delito y su resolución desde el derecho indígena: ¿el derecho estatal como autoridad moral?}

A los funcionarios estatales que intervinieron en este caso se les dificulta reconocer que un delito tan grave como la violación haya sido juzgado por una comunidad indígena y sus autoridades. El único lugar autorizado para tratar este delito es el derecho estatal y las únicas autoridades competentes son sus funcionarios, según sus argumentos. De esta manera, sin detenerse a observar sus graves límites, le otorgan al derecho estatal un estatus de superioridad moral y anulan las instancias históricas de resolución de conflictos de los pueblos indígenas. La antropóloga Rita Segato, en su texto "Que cada pueblo teja los hilos de su historia", plantea que la pretensión de superioridad moral es un instrumento de la dominación colonial (2011). Se defiende la idea de que la gente blanca y la cultura occidental tiene el deber de rescatar a las mujeres y los niños indefensos de los indígenas y negros crueles y bárbaros que no saben cuidar de su propia vida (Spivak, 1988; Segato, 2011). Así se inhabilita a los pueblos indígenas de su capacidad de cuidar y gestionar su propia vida.

Sin embargo, el derecho indígena siempre ha conocido y resuelto conflictos demandados tanto por hombres como por mujeres, y en estas circunstancias, ha atendido problemas de violencia contra las mujeres. Leticia Urizar (2000), Guisela Mayén y José Chaclán (2006) han documentado algunas de las formas de resolver problemas de violación, violencia física, psicológica y verbal; acusaciones de adulterio, demandas de separación, manutención, denuncias de alcoholismo e irresponsabilidad paterna y disputas por herencia, entre otros. Sus fundamentos y métodos en algunos casos han coincidido con los de la justicia oficial; en otros, muestran notorias diferencias. Mayén y Chaclán (2006) plantean cómo en las resoluciones del derecho indígena suele haber una mayor consideración hacia las mujeres, por la estima cultural y cosmogónica y la orientación reparatoria del derecho indígena. ${ }^{9}$ Asemejar a las mujeres con la madre tierra, verlas como seres sagrados por su lugar en la reproducción de la vida o velar por la idea de complementariedad en equilibrio entre hombres y mujeres, suelen ser fundamentos que guían las resoluciones cotidianas. Sin embargo, al igual que en el derecho oficial, otras resoluciones en el derecho indígena suelen ser favorables a los hombres, al culpar y revictimizar a las mujeres..$^{10}$ También el derecho indígena, debido a la historia de violencia de este país, puede ser influido por las nociones patriarcales dominantes en la sociedad guatemalteca.

Las autoridades indígenas de Comitancillo, lejos de consentir la violación, la trataron de inmediato como un problema grave y le dieron la categoría de delito. Los padres del menor agresor tampoco lo consintieron a él y sus actos, sino que asumieron una responsabilidad por atender a la menor, juzgar el hecho, disculparse con la niña y su familia, y se comprometieron a cuidar la salud de la afectada. El haber procurado que la niña fuera atendida en el hospital, luego por una comadrona, una ginecóloga

"La violación es uno de los casos más graves en contra de las mujeres, dentro del derecho maya en el municipio de Sololá. Para sancionar esta agresión primero se determina si el agresor es soltero o casado, dependiendo de ello así es el tipo de sanción. En el caso de ser hombre casado y que la víctima quede embarazada se aplican diversas sanciones, una de éstas es que el violador debe compensar a la ofendida dándole un terreno, puede también sancionarse con una compensación económica; además de cualquiera de las anteriores se le impone la obligación de una pensión alimenticia para el niño. Si la mujer no queda embarazada, se impone cualquiera de las dos primeras sin pensión alimenticia" (Mayén y Chaclán, 2006: 92). Esto coincide con lo que ocurre en el derecho occidental y sus estructuras, problema analizado ampliamente desde el feminismo y los estudios de género. Para Alda Facio (Rodríguez, 2008), el derecho tiende a culpar a las mujeres de los actos de violación cometidos en su contra y minimiza los efectos sufridos, pues responde a una cultura patriarcal. 
y un psicólogo, muestra que tanto los padres del menor, como las autoridades de la comunidad y las familias estuvieron preocupados y esta misma angustia los llevó a buscar soluciones efectivas para el entorno que posibilita su vida. La resolución implicaba garantizar que el hecho de la violación no se repitiera, para ello se decidió que el menor pidiera perdón de rodillas a sus padres, a los padres de la niña y a la niña. Pedir perdón de rodillas es un acto digno, un signo grande de arrepentimiento según prácticas indígenas antiguas y contemporáneas, como ocurre en otras culturas del mundo. Las palabras que las autoridades indígenas requirieron decir al menor están cargadas de un sentido de responsabilidad para integrar a las familias y a ambos menores en una convivencia social sin conflictos. El acto de violación cometido por el menor representa una vergüenza no sólo para él, sino para su familia, por ser el lugar en el que el menor ha formado su comportamiento. De allí surge la preocupación de la familia del joven por resolver el problema.

El sentido de los azotes en público que los padres dieron al menor se explica por el contexto. Fuera de él, se ve como un acto de barbarie que atenta contra los derechos humanos. La razón de hacerlo público es que los testigos representan el ojo vigilante del comportamiento futuro del menor. Esto servirá para proteger a la niña de otra posible agresión. De esta manera, existe menos posibilidad de que la violación se repita. Sin embargo, es sano mencionar que hay, como en otros métodos utilizados tanto en el derecho estatal como en el derecho indígena, controversia sobre el uso de los azotes. Para el señor Juan Zapeta, de la Defensoría Indígena de Santa Cruz del Quiche, los azotes son simbólicos, no se busca dañar físicamente a los azotados (Sieder y Flores, 2012). El representante del gran Consejo Nacional de Autoridades Ancestrales y su abogado han ilustrado también el fundamento cosmogónico de esta práctica. Por la relevancia de los azotes como un método en el ejercicio del derecho indígena en varios países de Latinoamérica, la jurisprudencia nacional e internacional los ha reconocido como una práctica válida (Cabedo, s. f.). Sin embargo, hay gente maya que opina que los azotes deben ser cuestionados por su uso colonial contra los indígenas. En todo caso, los funcionarios del derecho estatal no pueden desconocer que los mayas deciden con toda legitimidad los métodos de su propio sistema de justicia. Este debate interno debe ser respetado por el derecho estatal antes de ser utilizado de manera perversa para perseguir a quienes lo usan.

Por otro lado, por lo general, las resoluciones del derecho indígena no terminan con encarcelamiento debido a su orientación reparativa. ${ }^{11} \mathrm{El}$ agresor debe asumir la responsabilidad de atender las necesidades generadas en la víctima. Los padres del menor se comprometieron a sufragar los gastos en que incurriere el cuidado de la salud de la niña de seis meses a un año. Los funcionarios estatales dudan que esta responsabilidad se haya hecho efectiva, porque se mueven en un contexto en el que la palabra dada no tiene valor. En muchas comunidades, por lo tanto en el derecho indígena, la palabra sigue teniendo un gran valor y se empeña frente a los testigos del caso.

Para sellar su resolución, las autoridades indígenas invocaron el artículo 66 de la Constitución Política de la República de Guatemala y los artículos 5 y 8 del Convenio 169. Esto significa que el derecho indígena, como lo ha hecho siempre, se está abriendo a otras posibilidades para emitir una resolución. Este

11 Estudiosos del derecho indígena, como Edgar Esquit y Carlos Ochoa (2006), entre otros, han registrado cómo, al igual que el derecho occidental, el derecho maya se sustenta en una filosofía o cosmovisión que funciona como una aspiración máxima. El derecho maya se piensa como pacífico, preventivo, reparador y flexible. Es ejercido con el propósito de que la persona asuma una posición reflexiva sobre sus actos, con lo que pretende prevenir otras faltas. El diálogo y el valor de la palabra son ejercicios importantes (Esquit y García, 1998). 
reconocimiento de las leyes ilustra su dinamismo y le da ventaja frente al derecho estatal, que se considera impermeable a otras formas de ejercer el derecho que no sea el venido de la tradición occidental.

Esta resolución fue satisfactoria para las familias de ambos menores. Es decir, tuvo eficacia social. Aunque no es perfecta y puede ser criticable, es por mucho más satisfactoria que la cantidad de resoluciones dictadas por el derecho estatal. Pero para los funcionarios estatales parece que la eficacia social en la resolución del conflicto no importa, sino la ilegalidad de la resolución y los derechos individuales del menor agresor y de la menor agredida. La resolución correcta sería, según el derecho estatal, "sanciones socioeducativas de libertad asistida por el plazo de dos años y servicios a la comunidad por el plazo de dos meses", ${ }^{12}$ medidas que a todas luces se distancian de la lógica comunitaria y no se relacionan con un beneficio directo para la menor. En este caso, el derecho estatal pretende ser legalista aunque ineficaz, legalista aunque injusto, legalista aunque destructor. Para la abogada Alda Facio:

\begin{abstract}
Trabajar la violencia como un problema que puede ser resuelto por la vía penal únicamente es un grave error. Porque la vía penal, además de ser ineficiente y androcéntrica, está centrada en el castigo de los perpetradores, no en la restitución, rehabilitación o el resarcimiento de las víctimas. Y, más importante aún, no en el cambio de las estructuras sociales y mentales que mantienen y hasta promueven esta violencia (Rodríguez, 2008).
\end{abstract}

Castigar de forma comunitaria el hecho de la violación fue importante para proteger socialmente a la menor. Por lo que puede verse, ambas familias apoyaron emocionalmente a la niña, no la culparon del hecho, sino que colocaron la violación en el lugar del delito y el resarcimiento. Esto es importante, pues ser violada donde prima una cultura patriarcal significa llevar la vergüenza sobre el propio cuerpo.
Los cuerpos violados son estigmatizados como cuerpos apropiables, por lo tanto, vulnerables a futuras violaciones. Las niñas violadas llevan en silencio la ansiedad de cómo explicar a su futura pareja hombre que "ya no son vírgenes", dado el valor sociocultural de la virginidad. Cuando no han reflexionado sobre el problema de violación, están expuestas a aceptar la violencia masculina con resignación a cambio del favor de "quererlas". Por eso la violación es un problema grave y necesita ser atendido, en cualquier lugar y grupo humano. En el caso que nos ocupa, la violación fue un delito perseguido y sancionado.

La Ley contra el Feminicidio y Otras Formas de Violencia contra la Mujer (decreto 22-208) invocada por la Sala de la Corte de Apelaciones de la Niñez y la Adolescencia no está en contradicción con el derecho indígena. En su artículo 9 establece: "prohibición de invocar costumbres o tradiciones culturales para exculpar al agresor de la violencia contra la mujer". Como argumentaron el abogado defensor del menor, el representante de las Autoridades Ancestrales y su abogado, es evidente que no se exculpó al agresor, sino que se le impusieron sanciones morales, físicas y económicas efectivas para su contexto. El problema que se presenta es la interpretación de los conceptos "costumbres", "cultura" y "tradiciones", y su asociación a los pueblos indígenas. Por mucho tiempo, el derecho indígena ha sido llamado "derecho consuetudinario" o "costumbres", nociones que no reflejan su complejidad. El derecho indígena no se asienta "exclusivamente" sobre una suerte de repetición costumbrista. Ha cambiado a lo largo del tiempo y está abierto al cambio. Se dice "exclusivamente", porque toda sociedad e institución arrastra transformaciones y costumbres sobre la base de la repetición.

\footnotetext{
12 Archivo General de Tribunales, acta 00044-2012-00131, of. 1, 1 de octubre de 2012, Sala de la Corte de Apelaciones de la Niñez y la Adolescencia. Miguel Ángel Giordano Navarro, magistrado presidente.
} 
Edgar Esquit y Carlos Ochoa (2006) plantean que la noción de que el derecho indígena es una tradición que permanece estática e inalterable es un mito que desarrolló el mismo sistema colonial. Esta forma de entender el derecho indígena alimenta las visiones etnocéntricas y racistas, en tanto responsabiliza a los indígenas del "subdesarrollo" de su propio sistema normativo "cerrado". Así, si hay violencia en el ejercicio del derecho, es por "la naturaleza salvaje" de los indígenas y no por el contexto en el que viven. El derecho indígena puede interpretarse no sólo como una tradición cultural y un sistema de valores propios, sino como un sistema moldeado o influido por contextos políticos y económicos diversos en el tiempo. El derecho indígena, como cualquier otro, es y debe ser evolutivo, progresivo y deliberante. En esta lógica deben analizarse delitos como la violación y su resolución. No hay justificación que valga para minimizar ni ocultar este problema, más bien, debe colocársele en el centro del debate. Por eso es vital subrayar que aquí se está trascendiendo la vieja polarización entre el relativismo cultural y el universalismo. Desde el relativismo cultural, se entiende a los pueblos indígenas como "comunidades cerradas", estáticas e involutivas. Mientras el universalismo plantea que la cultura occidental es la medida de toda la evolución que ocurre en el planeta. Ni una ni otra tendencia son útiles para lo que aquí se analiza.

Por todo esto, el derecho indígena es y debe ser reivindicado como evolutivo, deliberante y progresivo. Es improcedente seguir viendo al derecho indígena como puro, estático o producto de la repetición de "costumbres" y "tradiciones". De allí que tanto su sustento filosófico como los métodos utilizados hoy pueden ser revisados y replanteados por los mismos indígenas. Es importante que el derecho indígena, en todo el país, trate de forma prioritaria la violencia contra las mujeres y las demandas de las mujeres. Desde hace varios años, organizaciones indígenas nacionales y locales realizan esfuerzos en esta dirección. Las mujeres y los hombres mayas son los primeros interesados en construir sociedades sanas y vivibles, por lo tanto, no conviene ocultar los problemas que amenazan o atentan contra la vida. Ambos sistemas de justicia están obligados a defender los derechos y la vida de las mujeres. El derecho estatal no está en posición de asumir una autoridad moral en esta materia sin caer en incoherencia.

¿Qué proponen los fiscales -hombres y mujeres- que adversan esta resolución, además de la anulación del derecho indígena, el castigo para el agresor y la persecución penal a las autoridades indígenas? ¿Los fiscales darían por cerrado el caso cuando el brazo de la justicia oficial, en forma de encierro y encarcelamiento, alcance al menor agresor y a las autoridades indígenas? ¿No sería más provechoso para la comunidad y la sociedad guatemalteca tomar este caso como una manera de desafiar las limitaciones de ambos sistemas de justicia? ¿No sería más enriquecedor aprovechar sus fortalezas, buscar una actuación coordinada y sacar una lección importante para pensar en una descolonización y despatriarcalización de la jurisprudencia? ¿No es esto más saludable para la sociedad?

Por otro lado, es necesario preguntar si los respetables fiscales han reflexionado sobre por qué las familias de los menores no decidieron acudir al sistema de justicia oficial. Sea ésta la razón principal o no, los indígenas saben que las instituciones del Estado nunca han tratado los problemas de los indígenas como prioritarios. ¿Cómo piensan los fiscales tratar el problema del racismo que aleja a los indígenas y las mujeres de la posibilidad de acudir al sistema de justicia oficial? ¿De nuevo se impone a las comunidades indígenas un Estado castigador? La justicia guatemalteca, en el lenguaje de los fiscales que adversaron la resolución de las autoridades indígenas, se atribuye una autoridad moral que no posee. El derecho oficial no puede atribuirse la calidad de agente perseguidor del derecho indígena sin caer en una injusticia, un delito y una aberración histórica, que anularía a los pueblos indígenas como sujetos colectivos de derechos. 


\section{Conclusiones}

\section{EL DERECHO INDÍGENA ES COMPATIBLE CON LOS DERECHOS DE LAS MUJERES Y LOS NIÑOS}

Los pueblos indígenas no son bárbaros que se destruyen a sí mismos, sino sociedades a favor de la vida que persisten a pesar de la violencia colonial y del Estado. Por ser sociedades vivas, son transformativas. El grave problema de violación contra la niña no puede verse como algo que pasa sólo entre indígenas, sino como resultado de la violencia extendida contra las mujeres en todo el país. Este problema no fue consentido por las autoridades indígenas, sino comprendido en su gravedad, reflexionado y sancionado de acuerdo con sus normas y procedimientos. Es decir, es improcedente que el derecho oficial persiga a las autoridades indígenas por su resolución. Si así ocurriera, sólo podría comprenderse como un mecanismo de criminalización mediante el cual el derecho oficial reproduce su carácter colonial.

Por otro lado, si la atención se concentra en sancionar a las autoridades indígenas, se pierde la posibilidad de reflexionar sobre los mecanismos utilizados en la resolución del caso, la cosmovisión desde la que se habló y actuó, la vinculación con los preceptos de la justicia oficial y la realidad en la que se actuó. Hay aspectos de la resolución que invitan a pensar en otros principios y preceptos éticos para resolver la violencia contra las mujeres. Por ejemplo, es fundamental reconsiderar la noción de persona atribuida a las mujeres. Si las mujeres son comparadas con la madre tierra, como lo invocaron las autoridades de Comitancillo, su cuerpo no podría ser violado porque es sagrado. A la madre tierra se le respeta y se le venera en la cultura maya porque es fundamental en el ciclo de la vida. Así, la persona individual, las mujeres, los hombres y los niños están íntimamente conectados con la colectividad.

Cualquier resolución en cualquier sistema de derecho tiene como desafío la reparación de la víctima y las condiciones para la no repetición del hecho, en este caso, la lección pública dada al menor victimario garantiza que exista un ojo social vigilante sobre él. También se propusieron mecanismos de reparación para la niña Vilma Carolina. Podría debatirse si son suficientes o no, de la misma manera en que pueden cuestionarse las resoluciones en el derecho oficial para estos casos. Sin embargo, este caso debería ser aprovechado para promover reflexiones familiares y comunitarias en torno a prevenir la violencia contra las mujeres. Éstas serían muy efectivas si se realizaran a partir del derecho indígena, pues tiene legitimidad comunitaria. La voz, la experiencia y las demandas de las mujeres indígenas en todo el país son vitales para reflexionar sobre el tipo de comunidad y sociedad que los pueblos mayas deseamos ser.

Se desconoce cómo ha afectado a ambos menores y sus familias la intervención del derecho estatal. Sería necesario saber cómo ha afectado la persecución del derecho estatal a las autoridades indígenas de Comitancillo. Una persecución de esta naturaleza genera temor y desautoriza a quienes lo ejercen. Así, el Estado provoca un vacío que es incapaz de llenar. Sin embargo, si estas autoridades continúan en el ejercicio de sus responsabilidades, este caso representa una gran oportunidad para poner mayor atención a las demandas de las mujeres y las denuncias de violencia contra ellas. Al igual que en esta comunidad, en todo el país, el problema de violencia contra las mujeres debe ser reflexionado de manera sistemática.

\section{DERECHO INDÍGENA Y DERECHO OFICIAL: DESCOLONIZACIÓN Y DESPATRIARCALIZACIÓN}

Es necesario transformar la percepción que se tiene de que el derecho indígena es estático, costumbrista, tradicionalista y que funciona con base en la repetición. El derecho indígena, al igual que el derecho estatal, tiene una historia, un contexto, es y debe ser 
deliberante y evolutivo. En este marco, el debate sobre los métodos utilizados por algunas autoridades indígenas, como los azotes, es provechoso. Si bien estas prácticas gozan de aceptación social y comunitaria, también hay voces discordantes en las mismas comunidades. Lo mismo opera para el derecho oficial con sus métodos punitivos y de encarcelamiento. Las sociedades cambian por voluntad propia como resultado de las reflexiones que se producen en su interior, pero también tienden a cerrarse como resultado de cualquier forma de persecución.

La experiencia de las mujeres indígenas ofrece críticas y propuestas a ambos sistemas de justicia, así han apostado por su transformación. El Estado debe responsabilizarse por realizar un trabajo masivo en el que ambos sistemas de justicia coloquen como centro de sus preocupaciones los derechos de las mujeres indígenas, en el marco de un proceso que evite la reproducción de mecanismos de colonización. Así es como ambos sistemas deben trabajar por un proceso de despatriarcalización y descolonización.

\section{DERECHO INDÍGENA Y DERECHO ESTATAL: COEXISTENCIA Y COORDINACIÓN}

El derecho estatal no está en posición de criminalizar y perseguir al derecho indígena por cualquier resolución que no le parezca satisfactoria. Cuando esto ocurre, el derecho estatal señala a los pueblos indígenas como enemigos de la justicia y reproduce, a partir del derecho mismo, las formas de dominación colonial y las estructuras racistas de la sociedad guatemalteca. Anular el derecho indígena es tomar el camino más simple y fácil. ¿Quién persigue al derecho oficial por las resoluciones insatisfactorias que emite cada día? De acuerdo con Rita Segato (2011), ante un sistema jurídico oficial deficiente, es mejor abrir camino para otros modelos, como la normativa de los pueblos indígenas y el pluralismo jurídico. En Latinoamérica y Guatemala, hay experiencias de coordinación entre ambos derechos, que han devenido en resoluciones eficaces y satisfactorias (Sieder y Flores, 2012). Para que esto ocurra, el derecho estatal no puede ignorar la historia de un país multiétnico, plural y multilingüe. No se puede pedir evolución a los pueblos indígenas si el mismo Estado guatemalteco y su sistema de justicia no evolucionan con el cuestionamiento del colonialismo interno y la reproducción del racismo desde el ámbito legal.

Concuerdo con Segato (2011) en que el Estado no es la agencia para prescribir e imponer, mediante amenaza y coerción, desenlaces para la trama de la historia de los otros pueblos que abriga. Su papel único es el de proteger el curso propio de cada pueblo para que delibere con libertad sobre lo que quiere ser, y velar por que eso ocurra sin presiones e intromisiones autoritarias, como ha sucedido en este caso. Por lo argumentado, el derecho estatal no puede criminalizar al derecho indígena sin caer en un delito, una grave incoherencia y una aberración histórica. D

\section{Bibliografía}

Cabedo Mallol, Vicente José, s. f., “La jurisdicción especial indígena de Colombia y los derechos humanos”, en Forum II: Propuestas de desarrollo constitucional y jurisprudencia: derecho indígena y derechos humanos. Disponible en línea: <http://www.alertanet.org/F2bVCabedo.htm>.

Cumes, Aura, 2009, '“Sufrimos vergüenza': mujeres k'iche' frente a la justicia comunitaria en Guatemala”, en Desacatos. Revista de Antropología Social, núm. 31, pp. 99-114.

Defensoría de la Mujer Indígena (DEMI), 2007, El acceso de las mujeres indígenas al sistema de justicia oficial de Guatemala, Ukab'wuj ke ixoqib'. Segundo informe, Defensoría de la Mujer Indígena, Guatemala. 
Esquit, Edgar e Iván García, 1998, El derecho consuetudinario, la reforma judicial y la implementación de los acuerdos de paz, Facultad Latinoamericana de Ciencias Sociales, Guatemala.

Esquit, Edgar y Carlos Ochoa, 2006, “¿Cómo ha surgido y evolucionado históricamente el derecho indigena en Guatemala?”, ponencia presentada en el Seminario Internacional "Experiencias y avances del derecho indígena en Guatemala en el contexto del pluralismo jurídico", Centro de Investigaciones Regionales de Mesoamérica, 6 al 8 de diciembre, Guatemala.

Facio, Alda, 1999, “Hacia otra teoría crítica del derecho”, en Alda Facio y Lorena Fries (eds.), Género y derecho, LOM, Santiago de Chile, pp. 15-44.

Mayén, Guisela y José Chaclán, 2006, "El derecho indígena maya en la actualidad”, ponencia presentada en Seminario Internacional "Experiencias y avances del derecho indígena en Guatemala en el contexto del pluralismo jurídico", Centro de Investigaciones Regionales de Mesoamérica, 6 al 8 de diciembre, Guatemala.

Pop, Amanda, 2000, "Racismo y machismo: deshilando la opresión”, en Morna Macleod y Luisa Cabrera Pérez-Armiñán (comps.), Identidad, rostros sin máscaras, Oxfam-Australia, pp. 111-140.

__ , 2001, "Huérfanos en derechos. El caso Rax Cucul”, en Pedro Pitarch y Julián López García (eds.), Los derechos humanos en tierras mayas. Politica, representaciones y moralidad, Sociedad Española de Estudios Mayas, Madrid, pp. 245-272.

Rodríguez Calderón, Mirta, 2008, "Entrevista a la jurista costarricense Alda Facio, experta en temas de género y derechos de la mujer. 'Tenemos que entender la violencia contra las mujeres como un producto cultural”, en Rebelión, 1 de diciembre. Disponible en línea: <http://rebelion.org/noticia.php?id=76787>. Consultado el 20 de febrero de 2015.

Sánchez Botero, Esther y Herinaldy Gómez Valencia, 2008, El peritaje antropológico como prueba judicial, Red Latinoamericana de Antropología Jurídica/Instituto Colombiano de Antropología e Historia, Bogotá.

Segato, Rita Laura, 2008, "Que cada pueblo teja los hilos de su historia: el argumento del pluralismo jurídico en diálogo didáctico con legisladores”, en Victoria Chenaut, Magdalena Gómez, Héctor Ortiz y María Teresa Sierra (coords.), Justicia y diversidad en América Latina. Pueblos indigenas ante la globalización, Centro de Investigaciones y Estudios Superiores en Antropología Social/Facultad Latinoamericana de Ciencias Sociales-Ecuador, México, pp. 357-381.

Sieder, Rachel, 1996, Derecho consuetudinario y transición democrática en Guatemala, Facultad Latinoamericana de Ciencias Sociales, Guatemala.

__ 2000, "La justicia y la democracia en América Latina”, en Jorge Solares (coord.), Pluralidad jurídica en el umbral de/ sig/o, Facultad Latinoamericana de Ciencias Sociales, Guatemala, pp. 37-50.

Sieder, Rachel y Carlos Yuri Flores (coords.), 2012, Dos justicias. Coordinación interlegal e interculturalidad en Guatemala, F\&G Editores/Casa Comal, Arte y Cultura/ Universidad Autónoma del Estado de Morelos, Guatemala.

Solares, Jorge, 2000, "Antropología jurídica: el gran mundo de la comunidad pequeña”, en Jorge Solares (coord.), Pluralidad jurídica en el umbral de/ sig/o, Facultad Latinoamericana de Ciencias Sociales, Guatemala, pp. 15-36.

Spivak, Gayatri Chakravorty, 1988, "Can the Subaltern Speak?”, en Cary Nelson y Lawrence Grossberg (eds.), Marxism and the Interpretation of Culture, University of Illinois Press, Urbana.

Urizar, Leticia, 2000, “El derecho consuetudinario en el contexto de las relaciones de género”, en Jorge Solares (coord.), Pluralidad jurídica en el umbral del sig/o, Facultad Latinoamericana de Ciencias Sociales, Guatemala, pp. 89-102. 